\title{
TOWARDS GENDER EQUALITY IN EDUCATION AND CAREER IN THE EARTH OBSERVATION AND GI SECTOR
}

\author{
B. Riedler ${ }^{1}$, Nathalie Stéphenne ${ }^{2}$, Estefanía Aguilar-Moreno ${ }^{3}$, Marie Jagaille ${ }^{4}$, Aida Monfort-Muriach ${ }^{3}$, Grazia Fiore ${ }^{5}$, Natassa \\ Antoniou $^{6}$
}

\author{
${ }^{1}$ Dept. of Geoinformatics Z_GIS, University of Salzburg, Austria - barbara.riedler@sbg.ac.at \\ ${ }^{2}$ Public Service of Wallonia, Belgium - nathalie.stephenne@spw.wallonie.be \\ ${ }^{3}$ INIT, University Jaume I, Spain - eaguilar@uji.es, amuriach@uji.es \\ ${ }^{4}$ Brittany Remote Sensing Group, France - marie.jagaille@imt-atlantique.fr \\ ${ }^{5}$ EURISY, Italy - grazia.fiore@eurisy.eu \\ ${ }^{6}$ EARSC, Belgium - natassa.antoniou@earsc.org
}

\section{Commission V}

KEY WORDS: gender gap, gender bias, gender inequality, STEM, Copernicus, GIS, EO

\begin{abstract}
:
Gender inequality is omnipresent in our society and in the field of education and training, the gender gap is especially evident in STEM (Science, Technology, Engineering and Mathematics) disciplines. While different studies have been conducted about potential reasons explaining this gap, little is known about gender inequality and underlying factors in the Earth Observation and Geoinformatics (EO*GI) domain. To close some parts of this knowledge gap, the initiative Women in Copernicus was established with the overall goal to make women working in the EO*GI field and especially in the Copernicus ecosystem more visible. This paper analyses the results of a survey of 462 women identifying reasons for not choosing STEM education and the barriers related to educational choices in their career path. The main obstacles that hinder choosing a STEM education for these women are stereotypes in society, missing female role models but also culture, television and society message transmitted by the media. The lack of selfconfidence is an essential factor in this choice and is also experienced as a barrier during individual career paths. This analysis provides insights valuable for political decisions making targeting at a gender-balanced work environment and emphasizes the importance of attracting more girls and young women towards a STEM education and supporting them during their career to reach skills and occupational equality and strengthen the economic development of the EO*GI sector.
\end{abstract}

\section{INTRODUCTION}

\subsection{Gender gap in STEM}

Gender inequality is omnipresent in our society with males being on average better positioned in social, economic, and political hierarchies (UNEP, 2013; WEF, 2019). The importance to reach gender equality is anchored most fundamental in the UN Sustainable development goal SDG 5 "Achieve gender equality and empower all women and girls". Within the European Union it is written in the European Gender Equality Strategy $2020-2025^{1}$ as well as in the recommendations of the Committee of Ministers on preventing and combatting sexism through "recalling that gender equality is central to the protection of human rights, the functioning of democracy and good governance, respect for the rule of law and the promotion of well-being for all, that it entails equal rights for women and men, girls and boys, as well as the same visibility, empowerment, responsibility and participation in all spheres of public and private life, and that it implies equal access to and distribution of resources between women and men". ${ }^{2}$

\footnotetext{
1 epws.org/gender-equality-strategy-2025

${ }^{2} \mathrm{rm}$.coe.int/CoERMPublicCommonSearchServices/DisplayDCTMConte nt? documentId $=090000168093 \mathrm{~b} 26 \mathrm{a}$
}

When focusing on education, the gender aspect is additionally included in SDG 4 "Ensure inclusive and equitable quality education and promote lifelong learning opportunities for all", emphasising the fact that education is essential for the socioeconomic situation as a way to minimize poverty. While disparity in access to education is strongest related to income, gender does play an additional role (UN, 2020). Even in countries where general access to education and training is given, often a huge gender gap is evident in educational choices, influencing later stages of career in STEM (Science, Technology, Engineering and Mathematics) disciplines.

The identification of factors influencing educational choices that in turn lead to gender disparity in STEM disciplines are recently studied. Several studies provide different possible explanations, such as relative strengths - girls being better in other disciplines compared to boys (OECD, 2019); lower confidence or poorer perception of abilities in some STEM subjects of girls (OECD, 2019); role-model function of female STEM teachers (Bottia et al., 2015); influence of society and family through gender stereotypes (Makarova et al., 2019) or gender role beliefs (Dicke et al., 2019); expectations to what type of jobs different subjects can contribute, where girls have the tendency to favour people or society- oriented work values, which are not perceived to be coupled with STEM discipline (Guo et al., 2018); or monetary expectation in later stage of career, which on contrary are often perceived to be coupled 
with STEM subjects and seem to be more important for boys (Rapport and Thibout, 2018, Guo et al, 2018).

McNally (2020) identified increasing perception of own abilities and the presence of female role models as one of the main factors of political relevance that could change the current situation. In line, several initiatives and associations have been created to reduce gender gap in STEM education, including some by the European Commission, such as Women in Digital Scoreboard observatory ${ }^{3}$, a program to specifically train women in digital skills and dedicated funding in $\mathrm{EU}$ Programmes (Fatourou et al., 2019).

In the European Union, females make up $\sim 35 \%$ of higher graduates in STEM-related disciplines. This existing gender gap dramatically increases at later stages and in higher decisionmaking career positions, both in academy and industry (EC, 2019; McNally, 2020). Also here the reasons are not fully clear, but gender bias seems to play a major role (Moss-Racusin et al., 2018), and societal and economic effects are enormous. Attracting more women to STEM education and supporting them during their career is crucial for skills equality, to reduce occupational segregation, but also strengthen the economic development (EIGE, 2021).

\subsection{Gender inequality in the $\mathrm{EO}$ * GI sector}

The Earth Observation and Geoinformatic and (EO*GI) sector is a relatively new sector with a rapid growth, especially on the EO-side, evaluated for the European industry latest in 2019 by EARSC $^{4}$. It has a high demand for technological often STEM skills, traditionally male dominated. While some initiatives provide local information about diversity and inclusion in the space sector (e.g. O'Brien et al., 2019), and other studies and projects emphasised the importance of gender equity in EO*GIrelated training and capacity building (e.g. Thapa et al., 2019), little is known about gender disparity and underlying factors in the EO*GI domain as such. Acknowledging the importance of gender-related topics in this sector, several initiatives with different thematic and regional focus are existing (Tab. 1 - to name some with no claim of being a complete inventory). To complement these initiatives and gain insights from women particularly active in the Copernicus sector, the initiative Women in Copernicus was founded.

\begin{tabular}{l|l}
\hline Initiative & Focus \\
\hline EUROGI Women in GI & Political \& regional: Europe / GIS \\
\hline Women in Geospatial+ & Networking \& mentoring: GIS \\
\hline Women in GIS & Networking \& mentoring: GIS \\
\hline African Women in GIS & Networking \& regional: Africa / GIS \\
\hline WinGRSS & Technical \& networking: EO / GIS \\
\hline Geochicas & Technical: Open Street Map / GIS \\
\hline Ladies of Landsat & Technical: Landsat data / EO \\
\hline Sisters of SAR & Technical: SAR data / EO \\
\hline Shemaps & Technical: drone / EO \\
\hline
\end{tabular}

Table 1. Examples of EO*GI initiatives with gender-related focus

\subsection{Women in Copernicus initiative}

Women in Copernicus (www.womenincopernicus.eu) is an initiative with the overall goal to make women working in the EO*GI field and especially in the Copernicus ecosystem more visible. Copernicus ${ }^{5}$ thereby is the European Union's Earth observation programme that is well known for providing open access to satellite and in-situ data and services, as well as programmes integrating universities, private companies and governmental agencies to enlarge the use of these provided data and services. Women in Copernicus promotes an inclusive and gender-balanced education and working environment in this sector. As a first step challenges, gender-related barriers, as well as facilitators during education, training and career of women actively working in these fields were identified through surveys and interviews. The results are broadcasted and disseminated to different target audiences using different formats to raise awareness for the importance of this topic. Together suggestions for improvements and possibilities to address explicitly girls and young women as the next generation working in these fields and support them during education and early career are developed. For exchange, support, but also identification of collaboration possibilities and joint activities, networking possibilities are offered and open to all women working or intending to work in the EO*GI field.

\section{WOMEN IN COPERNICUS SURVEY}

In June 2020 Women in Copernicus released a survey in 7 languages with 50 questions related to (a) demographic details (b) educational background and career path including skills, position, accomplishments, experienced gender inequalities during study and at work (c) experienced barriers (d) experienced facilitators and (e) reasons for gender inequality in STEM, EO*GI and Copernicus. The survey included predominantly rating scale questions with 5 categories (1: strongly disagree - 5: strongly agree) that allows for easy statistical interpretation, but also open questions to identify complementary factors. In total 462 women working in the EO*GI sector replied to the survey and from these 100 women also provided answers to the open questions.

While an overview of survey results ranging from full demographic and educational background to details of barriers and facilitators can be found in Jagaille et al. (2020), this paper focuses on the detailed analyses of reasons for not choosing STEM education and barriers and partly facilitators related to educational choices experienced by these women during their path.

\subsection{Profiles of survey participants}

Educational background: The majority of survey respondents either have an educational background in a STEM discipline themselves, mainly in the field of Natural science, mathematics and statistics (46\%) or Engineering, manufacturing and construction $(19 \%)$. While in the original survey multiple answers for 11 different educational background disciplines could be chosen (Jagaille et al., 2020), for further analyses here the categories were pooled in STEM, Non-STEM and Mixed educational background (Fig.1).

\footnotetext{
3 digital-strategy.ec.europa.eu/en/library/women-digital-scoreboard-2020

4 https://earsc.org/industry-facts-figures/\#1596546549480-37f7bee7$49 \mathrm{af}$
}

5 www.copernicus.eu/en 


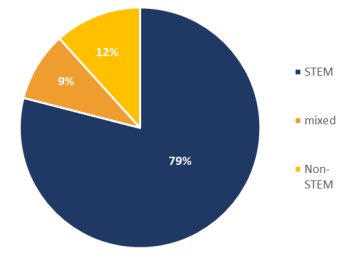

Figure 1. Educational Background

Age distribution: Most survey respondents are between 31 and 40 years old, followed by the age group of 41-50 (Fig.2). In the original survey 5 age classes were provided, but as only 7 women younger than $<25$ responded to the survey, the two lowest age classes were merged for analyses shown in this paper.

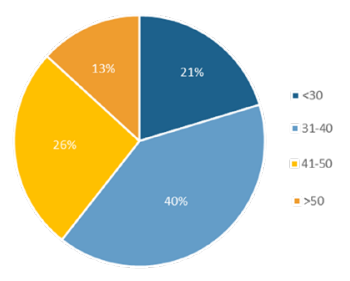

Figure 2. Age distribution

Organization type: The majority of survey respondents work in an academic setting, followed by private companies and governmental authorities (Fig.3). For further analyses, the category of Other was excluded.

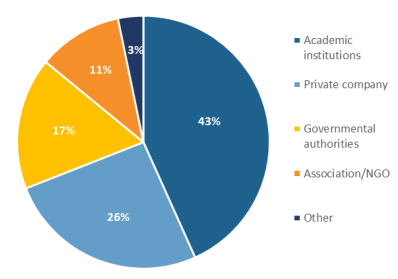

Figure 3. Organization type

To test dependencies between the profile variables age, educational background and organization type, $\mathrm{Chi}^{2}$ test were applied. No correlation between age and education type $(p=0.8240)$ as well as age and organisation type $(p=0.2391)$ could be found, while a correlation between education type and organisation type $(p=0,0006)$ is evident. This needs to be considered for the careful interpretation of the following results.

\section{REASONS BEHIND GENDER INEQUALITY}

\subsection{Reasons for gender gap in STEM education}

The main barriers for young women choosing a STEM education identified through this survey are stereotypes in society (average score: 3,89 ) and missing female role models (average score: 3,85 ), followed by influence of media (average score: 3,80 ), and the lack of self-confidence (average score: 3,78; Fig.4).

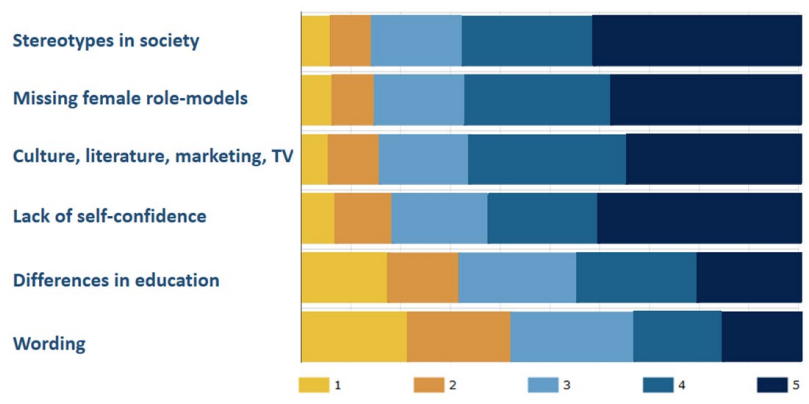

Figure 4. Barriers choosing STEM education

The two most important identified reasons are well in line with finding of other studies and independent of age, educational background or working sector. Although not statistically significant, women above 4lyears rate influence of media higher than younger females, while lack of self-confidence is especially by women younger than 30 years perceived as a main barrier for choosing a STEM education (Fig.5) and will be discussed later in detail.
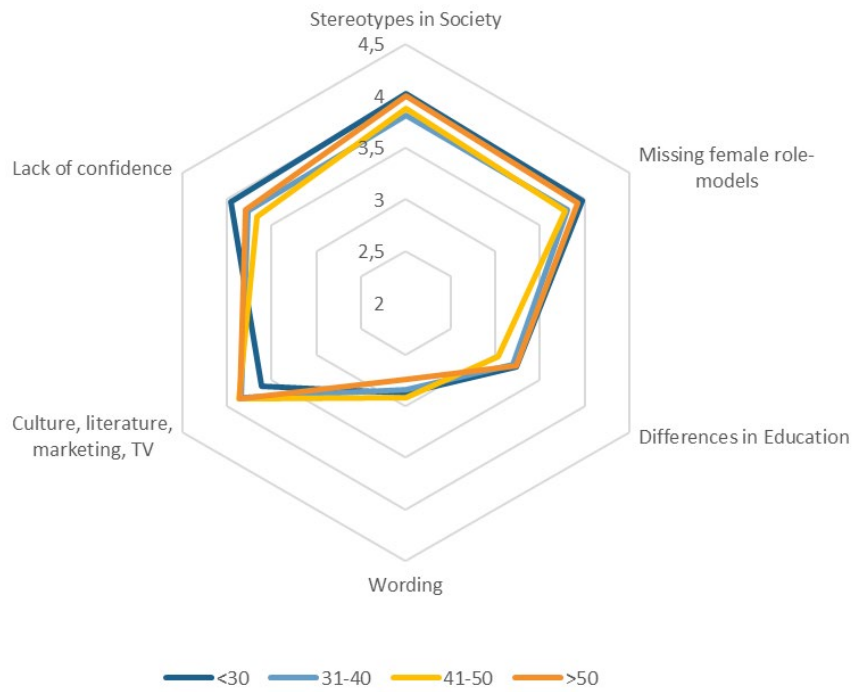

Figure 5. Barriers choosing STEM education depending on age

Difference in education (average score: 3,16), and wording (average score: 2,85 ) are in general perceived as less important barriers for choosing a STEM education, but are more important for women with an educational background in NonSTEM disciplines. (Fig.6). While not further tackled in this survey, one possible explanation for this difference could be that in social disciplines, law or education more attention to gender-sensitive wording is paid, and thus it's relevance is graded higher.

\subsection{Barriers and Facilitators for women working in the EO*GI sector related to educational choices}

Main barriers in the individual career paths of women working in the EO*GI and Copernicus sector are gender imbalance (average score: 3,58), gender bias (average score: 3,47), lack of self-confidence (average score: 3,34) and (potential) motherhood (average score: 3,19; Fig.7). The main facilitators 
are support of family during different stage of education and career (average score: 4,19), work satisfaction (average score: 4,12), and working environment that allows reconciliation of private and professional life (average score: 3,64; Jagaille et al, 2020).

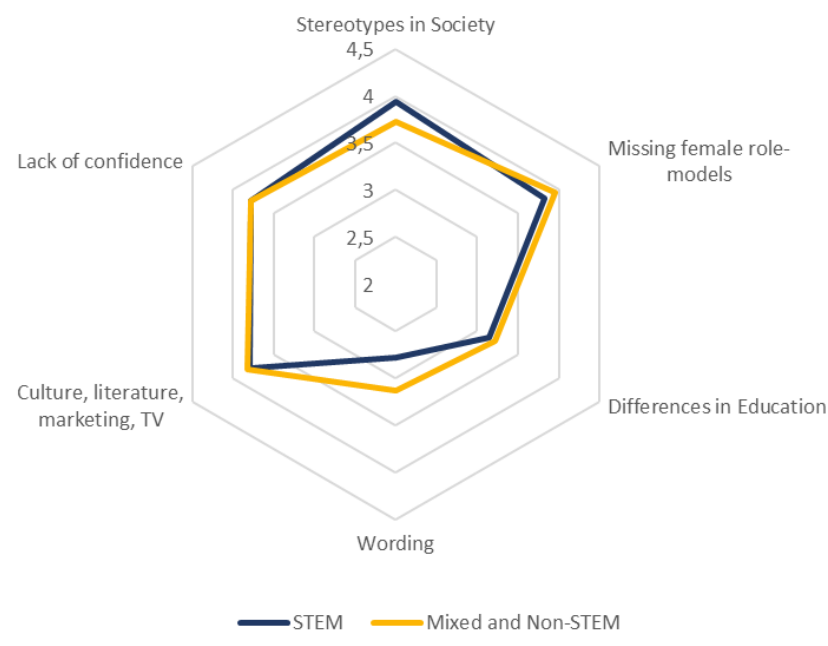

Figure 6. Bain barriers choosing STEM education depending on education type

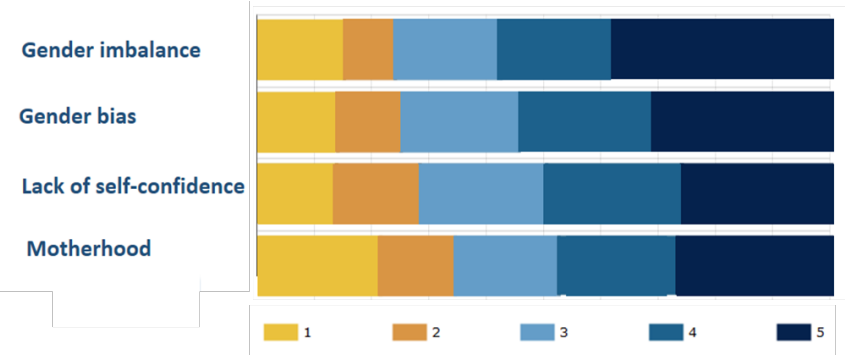

Figure 7. Barriers for women in the EO*GI sector

When focusing on barriers experienced during time of education, gender imbalance during study is one of the main barriers identified (average score: 3,58), independent on the women's profiles. Pressure from family or society to choose another domain/career option are barriers rated relatively low (average score: 1,75 , respectively 1.94 ).

The support of family during training and professional choice was on contrary perceived as one of the main facilitators for the career path of these women (average score: 4,11), a finding that is essential for future consideration. For the support of family and the much lower rated positive influence from society to choose the educational path (average score: 2,57), an age-gap around the age of 40 seems to be existing. For the encouragement during studies for an ambitious professional project (average score: 3,27), a clear age-dependent trend is visible (Fig.8). This finding directs towards existing trends and underlies the importance of positive motivation and mentoring during the educational paths, also in higher education, such as University studies.

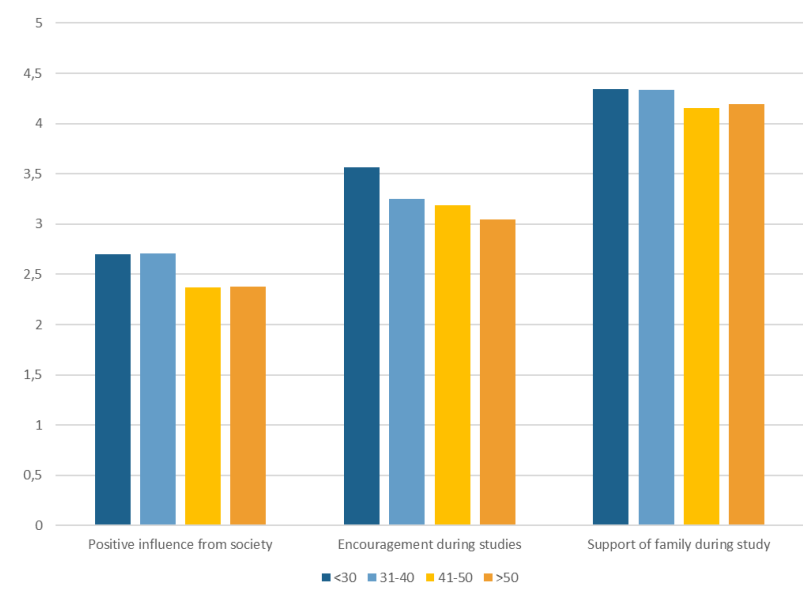

Figure 8. Facilitators related to education depending on age

\subsection{Common barriers for STEM education and career paths in the $E O * G I$ sector}

Lack of self-confidence is one factor that was identified as barrier for choosing a STEM education, but also experienced in the individual path of women of this study. The importance of additional aspects related to self-confidence, some even talking about imposture syndrome and the perception of being less talented or not taken seriously enough is especially visible in experiences in the individual career path of women (Tab.2) and was also often mentioned in testimonial speeches. While some other challenges are perceived less influential by younger women, suggesting a slow, but steady change in the perception and success of gender-related policies, lack of self-confidence is especially by women younger ( $<30$ years) perceived as a main reason for women not opting for a STEM education and career. This finding is in line with other studies revealing the existence of gender differences in self-perception of abilities during studies (OECD, 2019; OECD, 2015) and career (Herbst, 2020) and thus resemble an issues that should be tackled.

\subsection{Additional insights through qualitative analyses}

For the analyses of the open questions of additional reasons that can explain the low number of women in STEM and experienced barriers in individual career path, 3 main categories of based on the recurring pattern of answers were identified: 1) Discrimination and sexism 2) Concerns and fears related to study and career and 3) Stereotypes and expectations (Tab.2).

The first category pooling factors related to the discrimination, patriarchal society, sexism, equality policy and visibility of women in the STEM domain is with $86 \%$ of women answering to the open questions most often addressed. While these factors are relevant for both for STEM-related choices and barriers, they are of increasing importance at a later stage in career. The second category refers to fears and lack of support, where especially concerning about incompatibility of private and professing life are mentioned, which are perceived especially important when choosing a STEM educational path. The third category considers the expectation of women, but also the beliefs and gender stereotypes. Factors in this field are mainly identified as additional barriers in individual career paths $(47 \%$ compared to $34 \%$ in STEM choice). 


\begin{tabular}{l|l|l}
\hline Discrimination / sexism & STEM & career \\
\hline $\begin{array}{l}\text { Patriarchy / toxic masculinity / harassment / mansplaining / sexism / missing diversity / culture / religion / society } \\
\text { suggestion /age / unequal home tasks }\end{array}$ & 15 & 34 \\
\hline Boy club / male dominated sector / male leader/ perception of gender roles / gender imbalance & 16 & 26 \\
\hline Low visibility of women / minority feeling / missing women solidarity / mentorship / role models with children's & 10 & 12 \\
\hline Less job opportunity for women / ambition / career advancement / part-time contracts & 9 & 11 \\
\hline Discrimination in career / recruitment / glass ceiling (related with motherhood possibility) / recognition for part-time work & 4 & 16 \\
\hline Insufficient policy / need for new education models / need for quota - not disregarded & 6 & 6 \\
\hline Concerns and fears related to studies, career and life & & \\
\hline Difficulty of studies & 3 & 0 \\
\hline $\begin{array}{l}\text { Fear of imbalance of private and professional life / working environment to accommodate responsibilities / fear of travel / } \\
\text { presence, not result-orientated work / motherhood / reintegration after break / flexibility }\end{array}$ & 13 & 19 \\
\hline Family influence / tradition / religion & 13 & 5 \\
\hline School/teacher influence / lack of support-training to this kind of job & 11 & 7 \\
\hline Peer influence (other women sometimes unfortunately - queen bee syndrome) & 4 & 6 \\
\hline Unequal pay / cost of studies / economic crisis / coupled choice: women less paid / difficulty to hire home aid & 5 & 10 \\
\hline Stereotypes / expectations / beliefs & 13 \\
\hline Need of care / human / solving topics / emotion / empathy / listening & 4 \\
\hline Self-confidence "not for them"/ not dare / missing ambition, overprotection / impostor syndrome & 3 \\
\hline Copernicus is not only STEM and not inaccessible: beliefs & 8 \\
\hline Women are less clever / talented/ not seriously taken / should perform better / missing trust & 20 \\
\hline Raised to be pretty (dress code) / social pressure (succeed in everything) / raised to care, getting children & 1 \\
\hline
\end{tabular}

Table 2. Additional barriers mentioned in open questions

While drawing concrete conclusions from qualitative answers is challenging, they can complement quantitative results through providing details of reasons for gender disparity in STEM and highlight individual experiences in career paths of participants. Such details can provide additional insights that could be used by authorities to draw guidelines and best practice examples. Part of this enormous qualitative material is available in form of testimonial talks related to different topics and available on YouTube (Women in Copernicus). Listening to these personal testimonial talks and taking personal experiences and proposed solutions into account is an opportunity to actively involve women in this field and improve gender equality in the EO*GI sector.

Additionally survey respondents also pointed towards a missing visibility of STEM and space topics in general education, both for boys and girls. Concrete examples include missing or misleading knowledge about space careers and the prerequisites for choosing such a career path. Another mentioned misconception is that is not clear to everybody that STEM studies can play an important role in the contribution to solve societal problems, which is related to the findings that working for others is one factor for girls choosing a specific educational path (Guo et al., 2018). In line with Fitzsimmons (2018) quoting of the need to "urge industries traditionally dominated by one gender to send diverse role models to schools to talk about careers ", we argue that increased publicity about career opportunities when choosing STEM education related to the EO*GI sector in society and education can motivate girls and young women to join.

6 https://bel.uq.edu.au/article/2018/12/practical-measures-help-bridgegender-gap-young-adults

\section{CONCLUSION AND IMPLICATIONS}

The results of Women in Copernicus survey strengthen the importance for improved and gender-balanced education and working conditions to remove, or at least reduce stereotypes in education and society as a prerequisite to open the GI*EO sector to new female talents. As women in this sector are until now a minority, it is indispensable to motivate and support girls and young females to choose STEM education, which often is a prerequisite for a career in this domain.

The women in Copernicus, who participated in this survey, provided possible reasoning that hinder girls and young women choosing STEM careers and revealed most important barriers in education and career in the EO*GIS sectors together with dependency on age and educational background of women. The survey established at the start of the project asked women to quantify the impact of a selection of factors, seen a priori by the project as the most important ones. While rating of these factors give a highly valuable picture, they might also lack some diversity in individual experiences. Thus, this paper attempts to illustrate important additional underlying factors through analyses of open questions. While barriers are more on the side of gender imbalance, gender bias and the discrimination, sexism and patriarchy experiences during career path, the reasons for not choosing STEM studies more deal with aspects of stereotypes, beliefs and the lack of female role-models.

The importance of female role models and network possibilities in the EO*GI domain is assumed crucial to support female students during education and training and young professionals in capacity building and their (early) career. Thus, the Women in Copernicus invites all interested, especially women and female students, to follow the initiative on the website (www.womenincopernicus.eu), twitter (@WomenCopernicus) 
and YouTube (Women in Copernicus), participate in the networking options (LinkedIn group: Women in Copernicus) and offered activities and events, such as Webinar series (www.womenincopernicus.eu/events).

Universal barriers, such as lack of self-confidence, that play a crucial role in both STEM choice and individual barriers were identified. For setting political activities against stereotypes and toward an increasing equality in STEM education, the lack of self-confidence and poor perception of own abilities should be considered as priority for attracting the next generation of girls' talents to the EO*GI and Copernicus sector. As also encouragement during study, together with the support from family, is perceived as facilitator, mentoring during all stages of education should be targeted. As the view of this topic from students and young professionals is considered very important and could give additional insights in progressing change of perceived barriers, a survey specifically addressing students in the $\mathrm{EO}^{*} \mathrm{GI}$ sector resembling this age class is planned to be launched in 2021.

While figures of this survey are extracted from views of 462 women active in the EO*GI and Copernicus sector and qualitative analysis is based on answers given by 100 of these women, one cannot take these results for granted for the whole sector, but they give some first, maybe crucial, insights. In line with the increasing importance of the topic, e.g. in the Gender Equality strategy 2020-2025 of the European Commission, it seems the right moment to adopt a strong strategy to identify, trace and propose solution to minimize gender-related barriers. Findings and suggestions from this survey could be considered to achieve this overall goal of increase gender equality in the EO*GI sector.

\section{ACKNOWLEDGEMENTS}

Initial steps and research implemented received short-term and small scale funding from the project CoRdiNet (under the European Union's Horizon 2020 research and innovation program under grant agreement No. 821952). The majority of work was and is done voluntarily by founders of the initiative. We are grateful for all organisations that support and promote Women in Copernicus in various ways. A special thank is directed to all women that replied to the survey, took the time to answer interviews, provided self-recordings and are part of the initiative.

\section{REFERENCES}

Bottia, M.C., Stearns, E., Mickelson, R.A., Moller, S., Valentino, L., 2015, Growing the roots of STEM majors: Female math and science high school faculty and the participation of students in STEM, Economics of Education Review, 45, https://doi.org/10.1016/j.econedurev.2015.01.002

Dicke, A., Safavian, N., Eccles, J. S., 2019, Traditional Gender Role Beliefs and Career Attainment in STEM: A Gendered Story?, Frontiers in Psychology, 10, https://doi.org/10.3389/fpsyg.2019.01053

European Institute for Gender Equality, 2021, How gender equality in STEM education leads to economic growth, https://eige.europa.eu/gender-mainstreaming/policyareas/economic-and-financial-affairs/economic-benefits-genderequality/stem (19April 2021)
European Commission, 2019, She figures 2018, DirectorateGeneral for Research, https://doi.org/10.2777/936

Fatourou, P., Yota, P., Vasiliki, P., 2019, Women are needed in STEM: European policies and incentives. Communications of the ACM, https://doi.org/10.1145/3312565

Guo, J., Eccles, J. S., Sortheix, F.M., Salmela-Aro, K., 2018, Gendered Pathways Toward STEM Careers: The Incremental Roles of Work Value Profiles Above Academic Task Values, Frontiers in Psychology, 9, https://doi.org/10.3389/fpsyg.2018.01111

Herbst, T.H.H., 2020, Gender differences in self-perception accuracy: The confidence gap and women leaders' underrepresentation in academia, SA Journal of Industrial Psychology, https://sajip.co.za/index.php/sajip/article/view/1704/2746 (19April 2021)

Makarova, E., Aeschlimann, B., Herzog, W., 2019, The Gender Gap in STEM Fields: The Impact of the Gender Stereotype of Math and Science on Secondary Students' Career Aspirations , Frontiers in Education, 4, https://doi.org/10.3389/feduc.2019.00060

McNally, S, 2020, Gender differences in tertiary education: What explains STEM participation?, EENEEE Analystical Report No.41, Directorate-General for Education, Youth, Sport and Culture, https://doi.org/10.2766/421080

Moss-Racusin, C.A., Sanzari, C., Caluori, N, Rabasco., H., 2018, Gender Bias Produces Gender Gaps in STEM Engagement, Sex Roles, 79, https://doi.org/10.1007/s11199018-0902-z

O'Brian A.C., Martin L.J., Lee Roberts, S., 2019, the need for an Inclusive Space Sector: a Student Perspective, Proceedings, of the $3^{\text {rd }}$ Symposium on Space Educational Activities, https://doi.org/10.29311/2020.50

OECD, 2015, The ABC of Gender Equality in Education: Aptitude, Behaviour, Confidence, Chapter 3: Girl's Lack of Self-confidence, ilibrary.org/docserver/9789264229945-6-

en.pdf?expires $=1618837605 \&$ id $=$ id\&accname $=$ guest\&checksu $\mathrm{m}=\mathrm{F} 698 \mathrm{C} 111 \mathrm{DCE} 18 \mathrm{~B} 8 \mathrm{D} 3 \mathrm{E} 3688 \mathrm{E} 96 \mathrm{AD} 14 \mathrm{D} 62$ (19April 2021)

OECD, 2019, Why don't more girls choose to pursue a science career?, PISA in Foucs \#93, https://www.oecdilibrary.org/docserver/02bd2b68-

en.pdf?expires $=1618858187 \&$ id $=$ id\&accname $=$ guest $\&$ checksu $m=3 E D A 99352 D 5 A 7707 A 043 A 1379 A 27 F 372$ (19April 2021)

Rapoport B., and Thibout, C., 2018, Why do boys and girls make different educational choices? The influence of expected earnings and test scores, Economics of Education Review, 62, https://doi.org/10.1016/j.econedurev.2017.09.006

Thapa R.B., Matin, M.A., Bajracharya B., 2019, Capacity Building Approach and Application: Utilization of Earth Observation Data and Geospatial Information Technology in the Hindu Kush Himalaya, Frontiers in Environmental Science, https://doi.org/10.3389/fenvs.2019.00165 
United Nations Development Programme, 2013, Humanity Divided: confronting inequalities in developing countries, https://www.undp.org/content/undp/en/home/librarypage/povert y-reduction/humanity-divided--confronting-inequality-indeveloping-countries.html (19April 2021)

United Nations, 2020, The Sustainable Development Goals Report, https://unstats.un.org/sdgs/report/2020/ (19April 2021)

World Economic Forum, 2020, Global Gender Gap Report 2020, http://www3.weforum.org/docs/WEF_GGGR_2020.pdf (19April 2021) 